\title{
Aspectos fisiológicos, comportamentais e produtivos de cabras Alpinas submetidas ao transporte
}

\author{
Taissa de Souza Canaes ${ }^{1}$, João Alberto Negrão²
}

\author{
1 Pós-Graduação em Zootecnia - FCAVIUNESP, Jaboticabal, SP, Brasil. \\ 2 Departamento de Ciências Básicas - FZEA/USP, Pirassununga, SP, Brasil.
}

\begin{abstract}
RESUMO - Objetivou-se avaliar as alterações fisiológicas, produtivas e comportamentais em cabras da raça Alpina submetidas ao transporte. Foram utilizadas 12 cabras pluríparas em final de lactação. A produção, composição e contagem de células somáticas do leite e as respostas comportamentais das cabras durante a ordenha foram mensuradas três dias antes, no dia e três dias após o transporte. Também foram colhidas amostras de sangue antes (-120 e -10 minutos) e após (10 e 120 minutos) o transporte para determinação dos níveis de cortisol e glicose. Entre os comportamentos estudados durante a ordenha, apenas sobrepasso e coçar foram significativamente influenciados pelo transporte. Também foram observados aumentos significativos nos níveis de glicose e cortisol 10 minutos após o transporte. Os níveis de glicose permaneceram elevados até 120 minutos após o transporte, enquanto os de cortisol aos 120 minutos foram semelhantes aos observados antes do transporte. O transporte com retorno às instalações conhecidas e ao manejo rotineiro de ordenha causa pequenas alterações fisiológicas e comportamentais que não alteram significativamente a produção, a composição e a contagem de células somáticas do leite.
\end{abstract}

Palavras-chave: cortisol, estresse, glicose, qualidade, rendimento de leite

\section{Physiological, behavioral and productive response of Alpine goats submitted to transportation}

\begin{abstract}
The aim of this work was to evaluate the physiological, productive and behavioral variations in Alpine goats during transportation. Twelve multiparous Alpine goats at late lactation period were used. Milk production, composition and somatic cells count, as well as the behavioral responses of goats during milking were measured in three time periods: three days before transportation, in the transportation day and three days after transportation. Also, blood samples were collected $120 \mathrm{~min}$ and $10 \mathrm{~min}$ before transportation and equal period after transportation for cortisol and glucose dosages. Among the behaviors studied during milking, only overstep and grooming were significantly changed by transportation. Significant increases were observed on glucose and cortisol levels 10 minutes after transportation. Glucose levels remained high until 120 minutes after transportation; however, cortisol presented similar level from before transportation until 120 minutes after transportation. Thus, in the present study, transportation with return to known facilities and to milking routine caused little physiologic and behavioral variations that did not decrease milk production, composition and somatic cell count.
\end{abstract}

Key Words: cortisol, glucose, milk yield, quality, stress

\section{Introdução}

O transporte é um manejo inevitável, porém a severidade do estresse imposto nos diversos estágios desta prática, as circunstâncias e os métodos aceitáveis para reduzir seus efeitos adversos ainda estão em estudo (Grandin, 1997; Fazio \& Ferlazzo, 2003).

Neste contexto, algumas variáveis fisiológicas são comumente utilizadas para avaliar o tipo de estresse, entre elas, o aumento dos níveis de cortisol (Herd, 1989; Greenwood \& Shutt, 1992; Alberghina et al., 2001), a aceleração da gliconeogênese (Duvaux-Ponter et al., 2003) e o aumento das freqüências cardíaca e respiratória (Baldock \& Sibly, 1990; Rushen et al., 2001; Fazio \& Ferlazzo, 2003).

Apesar das poucas informações sobre o comportamento de cabras leiteiras, alguns autores têm comprovado efeito do transporte no comportamento de outras espécies, como suínos (Stephens \& Perry, 1990), bovinos (Friend et al., 1981; Trunkfield \& Broom, 1990; Warriss et al., 1995), eqüinos (Kusunose \& Torikai, 1996) e ovelhas (Baldock \& Sibly, 1990). 
Desta maneira, é fundamental avaliar as alterações fisiológicas e comportamentais causadas pelo transporte (Grandin, 1997; Fazio \& Ferlazzo, 2003), pois podem reduzir a produção e modificar as características físico-químicas e celulares do leite.

Assim, o objetivo neste trabalho foi avaliar a produção, a composição físico-química e celular do leite, o comportamento e as alterações fisiológicas em cabras Alpinas submetidas ao transporte.

\section{Material e Métodos}

O experimento foi conduzido no Laboratório de Fisiologia Animal da Faculdade de Zootecnia e Engenharia de Alimentos (FZEA/USP), em Pirassununga (latitude 215'이" sul, longitude $47^{\circ} 27^{\prime} 50^{\prime \prime}$ oeste e altitude de 630 metros). A região é considerada, segundo a classificação de Köppen, de clima do tipo Cwa, tropical, sazonal, e com duas estações bem definidas, verão chuvoso e inverno seco.

Foram utilizadas 12 cabras da raça Alpina na fase final da segunda lactação, com produção de leite $(1.380 \pm 160 \mathrm{~mL})$, peso $(62,25 \pm 1,80 \mathrm{~kg})$ e escore corporal uniformes. Os animais receberam, conforme recomendações do NRC (1981), silagem de milho como volumoso principal e concentrado à base de milho grão, farelo de soja, soja tostada e calcário. A silagem de milho, o sal mineral e a água foram fornecidos à vontade e o concentrado foi fornecido na ordenha da manhã. Os animais foram mantidos em sistema de semiconfinamento com acesso a um piquete de capim-tanzânia (Panicum maximum, Jacq.) com baixa disponibilidade de matéria verde.

Os animais foram colocados em caminhão especializado, modelo gaiola (carroceria aberta) e transportados $35 \mathrm{~km}$ dentro do Campus da FZEA/USP, saindo e retornando ao Laboratório de Fisiologia Animal (instalação conhecida e manejo habitual) após 60 minutos. Durante todo o período experimental, foram ordenhados em sistema de ordenha espinha de peixe, uma vez ao dia, em ordenhadeira mecânica com seis conjuntos de teteiras, regulada para manter 180 pulsações por minuto com vácuo ajustado a $44 \mathrm{kPa}$. A mesma pessoa efetuou todas as ordenhas experimentais (nos dias anteriores, no dia do transporte e nos dias subseqüentes).

Para mensuração da produção de leite, composição e contagem de células somáticas, foram colhidas amostras três dias antes e três dias após o transporte. A composição físico-química do leite e a contagem de células somáticas foram determinadas, respectivamente, por meio de leitor automatizado de densidade ótica (Infrared Analyser for milk, Bentley Instruments, Minnesota) e citômetro (Somacount
300, Bentley Instruments, Minnesota). Cada amostra de $50 \mathrm{~mL}$ de leite foi conservada com uma pastilha de bronopol (2-bromo-2-nitropropano-1,3-diol) e analisada até sete dias após a colheita.

Para análise dos níveis de cortisol e glicose, o sangue foi colhido da veia jugular das cabras Alpinas presas no canzil de ordenha. As colheitas de sangue foram realizadas no dia do transporte, antes (tempos -120 e -10 minutos) e após o evento (tempos 10 e 120 minutos). O sangue foi colhido em tubos heparinizados a vácuo, conservado em gelo até ser levado ao laboratório, onde foi centrifugado por 15 minutos, a $15^{\circ} \mathrm{C}$ de temperatura e $3000 \mathrm{x}$ g. O plasma obtido foi conservado a $-20^{\circ} \mathrm{C}$ até a determinação quantitativa de glicose e cortisol, realizada, respectivamente, por dosagens enzimática (kit Laborlab) e imunoenzimática (kit DSL Active).

O comportamento dos animais foi filmado durante sete dias (três dias antes do transporte, no dia do transporte e três dias após o transporte) (Tabela 1). As filmagens tinham duração de 1 hora e foram realizadas por meio de circuito de oito câmeras (câmeras de vídeo CCD MK0326E) instalado na sala de ordenha do Laboratório de Fisiologia Animal, de forma que os animais pudessem ser observados em ângulos diferentes. O circuito de câmeras foi conectado ao computador, onde as imagens foram gravadas e posteriormente analisadas utilizando-se o programa Super DVR 32 Server ${ }^{\circledR}$ (DVR 32 v 1.2)

Também foram monitorados, com auxílio de um cronômetro, o tempo entre a entrada do primeiro e do último animal experimental na sala de ordenha (a abertura do portão da sala de ordenha sinalizou o início desta etapa e o fechamento do canzil sinalizou seu término) e o tempo para ordenhar (incluindo higienização dos tetos: predipping e post-dipping; teste com caneca de fundo negro e repasse manual) cada cabra experimental, a saída da sala de ordenha sinalizou o término desta etapa.

Tabela 1 - Descrição dos comportamentos avaliados

\begin{tabular}{lc}
\hline Comportamento & Descrição \\
\hline Virada de lado & $\begin{array}{c}\text { Movimento do corpo para } \\
\text { o lado esquerdo ou direito } \\
\text { Movimento alternado dos } \\
\text { membros posteriores }\end{array}$ \\
Retirada de teteira & $\begin{array}{c}\text { Deferimento de movimentos } \\
\text { ocasionando a queda das teteiras, } \\
\text { intencionalmente ou não }\end{array}$ \\
Defecação & Ato de defecar \\
Micção & Ato de urinar \\
Coçar & Ato de coçar \\
\hline
\end{tabular}


As análises estatísticas dos resultados foram realizadas utilizando-se o PROC GLM do SAS (SAS, 2004), por meio de análise de variância (ANOVA), e o teste Tukey, para os contrastes entre as médias. Todos os resultados experimentais foram apresentados com médias e erro-padrão médio. Os dados comportamentais foram analisados pelo teste não-paramétrico de Kruskal-Wallis, seguido do teste de comparação múltipla de Dunn com nível de significância de 5\%.

\section{Resultados e Discussão}

Não foram encontradas diferenças significativas $(\mathrm{P}>0,05)$ na produção de leite (Tabela 2) antes e após o transporte, porém há relatos de que vacas submetidas ao transporte e à mudança no local de ordenha apresentaram redução significativa na produção de leite (Rushen et al., 2001), chegando a perder até $23 \%$ de sua produção (Porcionato, 2005).

Também não houve diferença estatística na composição do leite e na contagem de células somáticas entre os dias anteriores e posteriores ao transporte. Os teores de proteína, gordura e lactose mantiveram-se constantes durante as colheitas experimentais, o que indica que o transporte isolado não causou alterações significativas na qualidade do leite. Em geral, esses resultados diferem dos descritos na literatura para bovinos (Bruckmaier et al., 1993; Rushen et al., 1999) e caprinos (Brasil et al., 2000; Kannan et al., 2000; Kandim et al., 2006) submetidos a diversos tipos de estresse.

Os níveis de cortisol e glicose apresentaram variação significativa $(\mathrm{P}<0,05)$ entre os tempos de colheita no dia do transporte, com picos 10 minutos após o término do transporte (Tabela 3). Embora o nível de cortisol tenha retornado a valores próximos aos basais, o nível de glicose permaneceu elevado até a coleta aos 120 minutos após o transporte.

Tabela 2 - Produção, composição e contagem de células somáticas (CCS) do leite de cabras Alpinas antes e após o transporte

\begin{tabular}{|c|c|c|c|}
\hline Variável & Antes do transporte & Após o transporte & CV (\%) \\
\hline $\begin{array}{l}\text { Produção de } \\
\text { leite }(\mathrm{mL})\end{array}$ & $1.482 \pm 156 a$ & $1.504 \pm 155 a$ & 36,08 \\
\hline Gordura (\%) & $2,95 \pm 0,19 a$ & $3,05 \pm 0,26 a$ & 26,29 \\
\hline Proteína (\%) & $3,21 \pm 0,06 a$ & $3,22 \pm 0,05 a$ & 6,08 \\
\hline Lactose (\%) & $4,27 \pm 0,08 a$ & $4,26 \pm 0,09 a$ & 6,86 \\
\hline $\begin{array}{l}\text { CCS } \\
\text { (x } 10^{3} \text { células }\end{array}$ & $\begin{array}{l}1.429,33 \pm 268,06 a \\
s / m L)\end{array}$ & $936,50 \pm 341,15 a$ & 89,84 \\
\hline
\end{tabular}

Médias seguidas de mesma letra na mesma linha não diferem $(\mathrm{P}>0,05)$ entre si pelo teste Tukey.
Altas concentrações de cortisol (Becker et al., 1985; Greenwood \& Shutt, 1992; Dalin et al., 1993) e glicose (Nwe et al., 1996; Kannan et al., 2000) foram observadas em espécies submetidas ao transporte. Outros autores também observaram que as concentrações de cortisol e glicose permaneceram elevadas durante todo o transporte (Nwe et al., 1996). Contudo, alguns autores observaram em caprinos que, após o transporte, os níveis de glicose permaneceram elevados, enquanto os de cortisol voltaram aos níveis basais (Nwe et al., 1996; Kannan et al., 2000).

Como o estresse causa a ativação do sistema hipotálamopituitária-adrenal (Fazio \& Ferlazzo, 2003; Negrão et al., 2004), promovendo mobilização energética e aumento nos níveis de cortisol e glicose (Kent \& Ewbank, 1986; Kannan et al., 2000), provavelmente a manutenção de níveis elevados de glicose neste estudo foi resultado da mobilização das reservas de glicogênio no músculo e fígado (Kannan et al., 2000; Duvaux-Ponter et al., 2003).

Entre os comportamentos estudados (Tabela 4), apenas a micção não foi observada no momento das ordenhas experimentais. Os comportamentos virada de lado, retirada de teteira e defecação, apesar de observados, não diferiram estatisticamente $(\mathrm{P}>0,05)$ entre os dias analisados. Da mesma forma, Porcionato (2005), em estudo com vacas primíparas submetidas ao transporte e posterior ordenha, também não encontrou diferenças significativas para retirada de teteira, defecação e micção. Outros autores, no entanto, observaram que diversos tipos de estresse provocaram aumento na freqüência de defecação e micção na sala de ordenha (Rushen et al., 1999; 2001).

Neste estudo, diferenças significativas $(\mathrm{P}<0,05)$ foram observadas nos comportamentos sobrepasso e coçar, o que confirma relatos de outros autores, que classificaram o transporte como um agente estressor que pode causar medo e provocar uma variedade de respostas comportamentais em bovinos leiteiros (Bruckmaier et al., 1993; Rushen et al., 2001).

A diminuição da freqüência de sobrepasso pode estar relacionada ao comportamento de inatividade ou redução de movimentação que tem sido descrita como indicador de

Tabela 3 - Concentrações de cortisol e glicose no plasma de cabras Alpinas antes e após o transporte

\begin{tabular}{lcrc}
\hline & $\begin{array}{c}\text { Tempo } \\
(\mathrm{min})\end{array}$ & $\begin{array}{c}\text { Cortisol } \\
(\mathrm{ng} / \mathrm{mL})\end{array}$ & $\begin{array}{c}\text { Glicose } \\
(\mathrm{mg} / \mathrm{dL})\end{array}$ \\
\hline Antes do transporte & -120 & $2,5 \pm 0,50 \mathrm{~b}$ & $96,17 \pm 3,70 \mathrm{~b}$ \\
& -10 & $2,48 \pm 0,40 \mathrm{~b}$ & $94,24 \pm 6,00 \mathrm{~b}$ \\
Após o transporte & 10 & $21,53 \pm 3,40 \mathrm{a}$ & $153,14 \pm 14,90 \mathrm{a}$ \\
& 120 & $3,30 \pm 0,60 \mathrm{~b}$ & $153,40 \pm 8,60 \mathrm{a}$ \\
\hline
\end{tabular}

Médias seguidas de mesma letra na mesma coluna não diferem entre si $(\mathrm{P}>0,05)$ pelo teste Tukey. 
Tabela 4 - Freqüência do comportamento de cabras Alpinas avaliado na sala de ordenha antes, no dia e após o transporte

\begin{tabular}{lcc}
\hline Comportamentoavaliado & Período & Freqüência \\
\hline \multirow{4}{*}{ Virada de lado } & Antes & $3,96 \pm 1,15$ \\
& Dia do transporte & $1,67 \pm 0,93$ \\
Sobrepasso & Após & $2,63 \pm 0,78$ \\
& Antes & $162,12 \pm 10,50 \mathrm{a}$ \\
Retirada de teteira & Dia do transporte & $95,92 \pm 5,83 \mathrm{~b}$ \\
& Após & $119,83 \pm 9,80 \mathrm{bc}$ \\
& Dia do transporte & $7,62 \pm 2,91$ \\
Defecação & Após & $2,92 \pm 0,97$ \\
& Antes & $0,13 \pm 0,07$ \\
Coçar & Dia do transporte & $0,00 \pm 0,00$ \\
& Após & $0,04 \pm 0,04$ \\
& Antes & $0,25 \pm 0,12 \mathrm{~b}$ \\
& Dia do transporte & $1,83 \pm 0,64 \mathrm{a}$ \\
& Após & $0,46 \pm 0,16 \mathrm{~b}$ \\
\hline
\end{tabular}

Médias seguidas de mesma letra na mesma coluna não diferem entre si $(\mathrm{P}>0,05)$ pelo teste Kruskal-Wallis, com comparação múltipla de Dunn.

alterações negativas do bem-estar animal (Paranhos da Costa, 2005). Resultados de outros trabalhos realizados indicam que o transporte em caminhão causou perda de equilíbrio, queda e dificuldade de levantar (Kusunose \& Torikai, 1996; Das et al., 2001). Esses eventos podem ter levado os animais a reduzirem seus movimentos após o transporte, o que explicaria a baixa freqüência dos comportamentos virada de lado, sobrepasso e retirada de teteira após o transporte.

A duração de entrada na sala de ordenha (2:14 \pm 0:12 minutos) não diferiu $(\mathrm{P}>0,05)$ nos dias avaliados, assim, as cabras utilizadas no experimento permaneceram habituadas ao manejo pré-ordenha. Outros autores demonstraram que a alteração do ambiente e/ou do manejo de ordenha provoca agitação e dificulta a ordenha, causando inibição da ejeção do leite e aumento no tempo de ordenha em animais leiteiros (Marnet \& Negrão, 2000; Macuhova et al., 2002).

Entretanto, neste estudo, a produção de leite foi estável e houve, inclusive, diminuição $(\mathrm{P}<0,05)$ no tempo de ordenha após o transporte, que passou de 22:03 \pm 2:27 minutos nos dias anteriores para 16:46 \pm 3:21 minutos no dia e 14:31 \pm 1:21 minutos nos dias subseqüentes ao transporte. Estes dados indicam que o fluxo de leite durante a ordenha foi maior após o transporte e que a ejeção do leite não foi alterada pelo transporte e pelo retorno das cabras experimentais às instalações já conhecidas. Conseqüentemente, o transporte, isoladamente, não causou alteração na produção, composição e contagem de células somáticas do leite.

\section{Conclusões}

Neste estudo, o transporte (com retorno às instalações conhecidas e ao manejo rotineiro de ordenha) foi um agente estressor momentâneo que provocou apenas alterações fisiológicas e comportamentais, mas não ocasionou redução na produção ou alteração na composição e na contagem de células somáticas do leite.

\section{Literatura Citada}

ALBERGHINA, D.; MEDICA, P.; FAZIO, E. et al. Effect of long distance road transport on serum cortisol and haematocrit in Limousine calves and influence of body weight decrease. Biotechnology, Agronomy Society and Environment, v.5, p.73, 2001.

BALDOCK, N.M.; SIBLY, R.M. Effects of handling and transportation on the heart rate and behaviour of sheep. Applied Animal Behaviour Science, v.28, p.15-39, 1990.

BECKER, B.A.; NIENABER, J.A.; CHRISTENSON, R.K. et al. Peripheral concentrations of cortisol as an indicator of stress in the pig. American Journal of Veterinary Research, v.46, n.5, p.1034, 1985.

BRASIL, L.H.A.; WECHESLER, F.S.; BACCARI JR., F. et al. Efeitos do estresse térmico sobre a produção, composição química do leite e respostas termorreguladoras de cabras da raça Alpina. Revista Brasileira de Zootecnia, v.29, p.16321641, 2000.

BRUCKMAIER, R.M.; SCHAMS, D.; BLUM, J.W. Milk removal in familiar and unfamiliar surroundings. Concentrations of oxytocin, prolactin, cortisol and $B$-endorphin. Journal of Dairy Research, v.60, p.449-456, 1993.

DALIN, A.M.; MAGNUSSON, U.; HÄGGENDAL, J. et al. The effect of transport stress on plasma levels of catecholamines, cortisol, corticotrophin binding globulin, blood cell count and lymphocyte proliferation in pigs. Acta Veterinaria Scandinavica, v.34, p.59-68, 1993.

DAS, K.S.; SRIVASTAVA, B.B.; DAS, N. Standing orientation and behaviour of goats during short-haul road transportation. Smal Ruminant Research, v.41, n.1, p.91-94, 2001.

DUVAUX-PONTER, C.; ROUSSEL, S.; TESSIER, J. et al. Physiological effects of repeated transport in pregnant goats and their offspring. Animal Research, v.52, p.553-566, 2003.

FAZIO, E.; FERLAZZO, A. Evaluation of stress during transport. Veterinary Research Communications, v.27, p.519-524, 2003.

FRIEND, T.H.; IRWIN, M.R.; SHARP, A.J. et al. Behaviour and weight loss of feeder calves in a railcar modified for feeding and watering in transit. International Journal for the Study of Animal Problems, v.2, p.129-137, 1981.

GRANDIN, T. Assessment of stress during handling and transport Journal of Animal Science, v.75, p.249-257, 1997.

GREENWOOD, P.L.; SHUTT, D.A. Salivary and plasma cortisol as an index of stress in goats. Australian Veterinary Journal, v.69, p.161-163, 1992

HERD, R.M. Serum cortisol and stress in cattle. Australian Veterinary Journal, v.66, p.341-342, 1989.

KANDIM, I.T.; MAHGOUB, A.K; AL-MARZOOQI, W. et al. Effects of transportation at high ambient temperatures on physiological responses, carcass and meet quality characteristics of three breeds of Omani goats. Meat Science, v.73, p.626 634, 2006.

KANNAN, G.; TERRILL, T.H.; KOUAKOU, O.S. et al. Transportation of goats: effects on physiological stress response and live weight loss. Journal of Animal Science, v.78, p.1450-1457, 2000. 
KENT, J.E.; EWBANK, R. The effect of road transportation on the blood constituents and behavior of calves. I. Six months old. British Veterinary Journal, v.139, p.228-235, 1986.

KUSUNOSE, R.; TORIKAI, K. Behavior of untethered horses during vehicle transport. Journal of Equine Science, v.7, p.21-26, 1996.

MACUHOVA, J.; TANCIN, V.; KRAETZL, W.D. et al. Inhibition of oxytocin release during repeated milking in unfamiliar surroundings. The importance of opioids and adrenal cortex sensitivity. Journal of Dairy Science, v.69, p.63-73, 2002.

MARNET, P.G.; NEGRÃO J.A. The effect of a mixed-management system on the realease of oxytocin, prolactin and cortisol in ewes during suckling and machine milking. Reproduction, Nutrition, Development, v.40, p.271-281, 2000.

NATIONAL RESEARCH COUNCIL - NRC. Nutrient requirements of goat: angora, dairy, and meat goats in temperate and tropical countries. Washington: National Academy Press, 1981. 91p.

NEGRÃO, J.A.; PORCIONATO, M.A.F; de PASSIELlÉ, A.M. et al. Cortisol in saliva and plasma of cattle after ACTH administration and milking. Journal of Dairy Science, v.87, p.1713-1718, 2004.

NWE, T.M.; HORI, E.; MANDA, M. et al. Significance of catecholamines and cortisol levels in blood during transportation stress in goats. Small Ruminant Research, v.20, p.129-135, 1996.
PARANHOS DA COSTA, M.J.R. O bem-estar no ambiente de produção. In: REUNIÃO ANUAL DA SOCIEDADE BRASILEIRA DE ZOOTECNIA, 42., 2005, Goiânia. Anais... Goiânia: Sociedade Brasileira de Zootecnia, 2005. p.395-399.

PORCIONATO, M.A.F. Adaptação de vacas das raças Holandesa e Girolando à ordenha. 2005. 75f. Tese (Doutorado em Zootecnia) - Faculdade de Ciências Agrárias e Veterinárias, Universidade Estadual Paulista, Jaboticabal, 2005.

RUSHEN, J.; De PASSIELLE, A.M.; MUNKSGAARD, L. Fear of people by cows and effects on milk yield, behavior and heart rate at milking. Journal of Dairy Sicence, v.82, p.720-727, 1999.

RUSHEN, J.; MUNKSGAARD, L.; MARNET, P.G. et al. Human contact and the effects of acute stress on cows at milking. Applied Animal Behaviour Science, v.73, p.1-14, 2001.

STATISTICAL ANALYSIS SYSTEM - SAS. SAS/STAT: user's guide, version 9.1. Cary: 2004. 842p.

STEPHENS, D.B.; PERRY, G.C. The effects of restraint and handling during simulated and real transport of pigs. Applied Animal Behaviour Science, v.28, p.41-55, 1990.

TRUNKFIELD, H.R.; BROOM, D.M. Welfare of calves during handling and transport. Applied Animal Behaviour Science, v.28, p.135, 1990.

WARRISS, P.D.; BROWN, S.N.; KNOWLES, T.G. et al. The effects on cattle of transport by road for up to fifteen hours. Veterinary Record, v.136, p.319-323, 1995. 